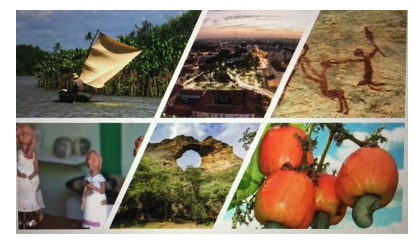

\title{
MULTICULTURALISMO E EDUCAÇÃO: O ESPAÇO DA GESTÃO
}

\author{
Renan Santiago de Sousa, \\ Doutorando em Educação pelo (PPGE/UFRJ) \\ Lattes ID: http://lattes.cnpq.br/8733974403799472 \\ Daniele Gomes da Silva \\ Doutorando em Educação pelo (PPGE/UFRJ) \\ http://lattes.cnpq.br/5334792037905586
}

Teresa Paula Nico Rego Gonçalves Doutora em Educação pela Universidad de Sevilla Professora Adjunta da Faculdade de Educação da UFRJ http://lattes.cnpq.br/9101792815651430

\begin{abstract}
RESUMO: Este artigo tem como objetivo analisar como questões de interesse do multiculturalismo, como diferenças de raça, gênero e sexualidade, perpassam o cotidiano da gestão de uma escola particular localizada à zona oeste da cidade do Rio de Janeiro. Parte-se do pressuposto de que uma gestão realmente democrática não pode deixar omisso o tratamento de tais assuntos. Para tal, foi feita uma análise documental do Boletim Informativo da escola, observações do conselho de classe relativo ao ensino fundamental I junto à mesma e uma entrevista semiestruturada com a diretora adjunta da instituição. De forma geral, os resultados apontam para uma dicotomia: embora a escola teoricamente se esforce em tratar positivamente de problema relacionados com as diferenças culturais junto aos discentes, foi notado que parte da equipe gestora e parte das(os) professoras(es) parece reproduzir estereótipos relacionados ao gênero e à sexualidade.
\end{abstract}

PALAVRAS-CHAVE: Gestão democrática. Gestão escolar. Multiculturalismo.

\section{MULTICULTURALISM AND EDUCATION: THE SPACE OF THE MENAGEMENT}

\begin{abstract}
This article aims to analyze questions of interest of multiculturalism, such as differences of race, gender and sexuality, perpass the daily life of a private school located in the western zone of the city of Rio de Janeiro. It takes in consideration that a really democratic school menagement cannot neglect these issues. For that, a documentary analysis of the School Information Bulletin, observations of class concil and a semi-structured interview with a director of the institution were done. In general, the indicators point to a dichotomy: although the school theoretically strives to deal positively
\end{abstract}




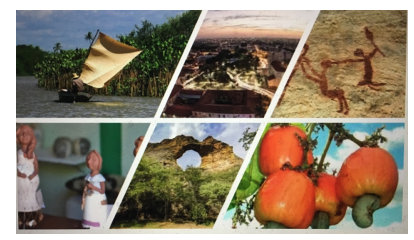

with the students, it was noted that part of the management team and part of the teachers seems to reproduce a stereotypes related to gender and sexuality.

KEY-WORDS: Democratic management. School management. Multiculturalism.

\section{MULTICULTURALISMO Y EDUCACIÓN: ÉL ESPÁCIO DE LA GESTIÓN}

RESUMEN: Este artículo tuvo como objetivo analisar como las cuestiones de interés del multiculturalismo, como las diferencias de raza, género y sexualidad, están presentes en la vida cotidiana de una escuela privada ubicada en la zona oeste de la ciudad de Río de Janeiro. Parte del supuesto de que uma gestión democrática no puede se omitir a estas questiones. Para esto, se realizó un análisis documental del Boletín de Información Escolar, observaciones de reuniones de maestro y una entrevista semiestructurada con una directora de la institución. En general, los indicadores apuntan a una dicotomía: aunque teóricamente la escuela se esfuerza por tratar de manera positiva tales questiones con los estudiantes, se observó que parte del equipo de administración y parte de los maestros há reproducido estereotipos relacionados con el género y la sexualidad.

PALABRAS CLAVE: Gestión democrática. Gestión escolar. Multiculturalismo.

\section{Multiculturalismo e Educação}

Atualmente, a contemporaneidade é marcada pela diferença, sobretudo, pelas diferenças culturais. Mudanças socioestruturais e socioculturais iniciadas ainda no último século continuam a se perdurar nos dias de hoje, reforçando as diferenças que existem entre as pessoas e estimulando-as a assumir suas identidades, lutando, dessa forma, contra concepções conservadoras que oprimem diversas formas de vida historicamente oprimidas-e marginalizadas.

Nessa perspectiva, pode-se perceber que a ascensão política de movimentos sociais, principalmente das centrais sindicais, do movimento negro, do movimento de Lésbicas, Gays, Bissexuais e Transgêneros, Transexuais, Travestis e Queers (LGBTTTQ) e dos movimentos feministas, corrobora para tal "virada cultural" (HALL, 1997), disponibilizando no ideário do pensamento social brasileiro outras concepções de mundo que destoam de um pensamento tradicional, estruturado por noções rígidas e restritas a respeito de raça, classe e gênero. 


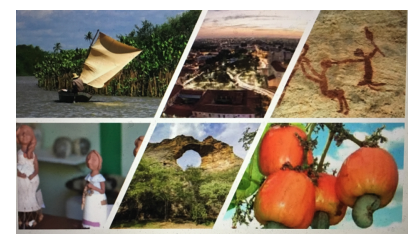

Destaca-se a importância do crescimento de tais movimentos, pois o pensamento conservador, outrora oferecido de forma hegemônica, pode causar diversos tipos de preconceitos e discriminações contra identidades que fogem da norma ocidental, ou seja, negros(as), indígenas, homossexuais, imigrantes, mulheres, moradores(as) de periferias, confessores(as) de religiões de matrizes africanas ou afro-brasileiras etc. Logo, o atual momento do país se configura em uma época na qual diversos grupos têm resistido - ou tentado resistir - à opressão sociocultural.

Pode-se dizer que uma das bases de um pensamento antirracista e antidiscriminatório é o multiculturalismo. Mais do que uma realidade de uma sociedade constituída por pessoas de diferentes grupos socioculturais, o multiculturalismo também se constitui em conjunto de ideias e ações que buscam gerir as diferenças, com o propósito de evitar hegemonias ou a opressão de um grupo direcionada a outro (HALL, 2003a, 2003b).

Dentro desta perspectiva, a escola ganha destaque como instituição plural, que recebe estudantes de diferentes grupos e classes, tornando-a sujeita às diferentes situações de discriminação, mas também possibilitando que em seu interior as(os) estudantes possam aprender com/sobre as diferenças, compartilhando experiências positivas, ensinando, aprendendo, hibridizando e convivendo com as diferenças.

Portanto, o multiculturalismo ganha espaço na educação, constituindo-se como uma filosofia educacional que busca a reforma educacional a modo de contemplar a pluralidade cultural (GAY, 1994), ao incorporar no cotidiano escolar indíviduos de grupos que historicamente têm menor acesso à escola (CANEN, 2007), com o objetivo de propiciar que esta seja, cada vez mais, gerida pela democracia com vista à justiça social, o que poderá influenciar positivamente a sociedade no futuro (DINIZ-PEIREIRA; ZEICHNER, 2008).

Atualmente, diferentes autoras(e)s têm pensado na questão do multiculturalismo atrelada à educação em diferentes campos e disciplinas, como no ensino de Artes (MIGON; NOGUEIRA 2015; SANTIAGO, 2017; CARDOSO JUNIOR, 2016), ensino 


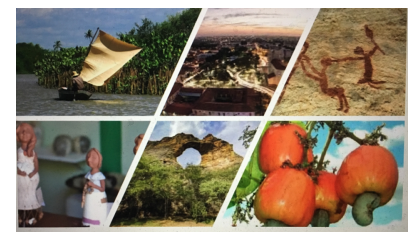

de Biologia (GUIMARÃES et al., 2013; DORVILLÉ et al., 2015), ensino de Educação Física (SALLES, 2014; SANTOS, 2013; GOMES, 2011; SILVA, 2008), ensino de Português/Línguas Estrangeiras (SOUSA; SODRÉ, 2012; FARIA, 2009; COSTA, 2001), História (ARAUJO, 2012; OLIVEIRA, 2010) entre outras disciplinas.

A revisão bibliográfica acima não buscou esgotar o tema, mas sim mostrar que o multiculturalismo tem sido bem aceito na educação e utilizado como referencial teórico para analisar o currículo e práticas pedagógicas de diferentes disciplinas. Porém, tais trabalhos têm em comum o fato de tratarem da prática docente, porém, sem levar em consideração uma esfera muito importante na área supracitada: a área da Gestão Educação.

Nesse quesito, ou seja, trabalhos que relacionassem Gestão Educacional e multiculturalismo, pôde ser verificado que estes são menos abundantes, porém, também se fazem presentes na produção acadêmica brasileira. Alguns exemplos:

Delatorre (2012) analisou como se constrói uma gestão escolar em uma escola multicultural do município de São José das Missões - RS, chegando à conclusão que tal escola valoriza as diferenças, levando tal aspecto em consideração na construção de sua gestão democrática.

Semelhantemente, Souza et al. (2015) analisaram a práxis de um gestor escolar, verificando que, embora tal gestor valorizasse o ideário do multiculturalismo, algumas de suas ações parecem ir contra às concepções de tal referencial teórico e da própria gestão democrática em si.

Já Carvalho (2012) teceu considerações importantes sobre as relações entre gestão democrática e diversidade cultural, enfatizando que tal questão transcende, muitas vezes, os limites da escola, abrangendo problemáticas históricas que estimulam as desigualdades sociais e influenciam toda a sociedade e não somente o espaço escolar.

A pesquisa de Canen e Xavier (2012) contribui com a discussão, ao analisar a gestão do currículo em um curso de formação continuada de professor(as)es, concluindo que a gestão pode contribuir com a formação de docentes sensíveis às diferenças culturais. 


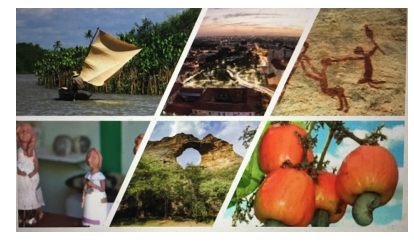

Por fim, Dantas e Gomes (2016) focam-se no papel da gestão escolar de uma escola quilombola para o pleno atendimento da Lei 10.639/2003, que trata da inclusão de conteúdos relativos à história e cultura afro-brasileira e africana no currículo escolar. Os autores concluem que o caráter democrático e dialógico da gestão possibilitou o cumprimento da Lei citada na escola em questão.

Desse modo, percebe-se que, embora não seja novidade tentar fazer dialogar o multiculturalismo com a gestão, tal relação pode ser analisada por diferentes ângulos, focando-se em diferentes objetos e situações de pesquisa.

A presente pesquisa parte da problematização do pensamento iluminista - que uniformiza(va) o alunado, tratando todas(os) as(os) estudantes como seres ideais, menosprezando as peculiaridades individuais - que busca substituí-lo por uma concepção que entende o espaço escolar como um lugar plural. Assim sendo, o gestor deve-se conceber a escola como um lugar onde "tudo acontece" (VIEIRA, 2009), ou seja, nela ocorrem fenômenos positivos, como hibridismos, trocas de experiências, aprendizagem mútuas etc., mas não se pode negar que no ambiente escolar também é propício a racismos, discriminações, bullyings e outros fenômenos sociais negativos fomentados pela não aceitação da diferença. Argumenta-se que a gestão, por meio de uma liderança pedagógica, organizacional e relacional, pode ser um caminho para mostrar às(aos) alunas(os) e professoras(es) os aspectos positivos do convívio em meio às diferenças.

Um possível caminho para a gestão escolar lograr êxito neste intento é a gestão democrática. Segundo Vieira (2007), a gestão democrática se opõe a uma gestão centralizada não apenas por exceder a questão do gestor ter sido escolhido democraticamente, mas também por apresentar outras características, como a existência de processos participativos nas tomadas de decisões, pela oportunização da formação de representação discente e pela cessão de voz e escuta às(aos) docentes, demais funcionários e responsáveis, bem como a valorização de todas e quaisquer tipos de ações democráticas no ambiente escolar, a fim de rechaçar ações anti-democráticas. 


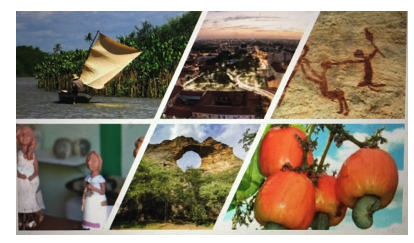

Tal gestão democrática inicia-se desde a construção do Projeto Político Pedagógico (PPP), que deve nascer de uma cooperação conjunta de toda a comunidade escolar. Temse também que a existência de Conselhos de Classe, Conselhos Escola-Comunidade e Conselho Escolares também são características de uma Gestão Democrática que busca ouvir diferentes interesses e implementá-los no dia a dia da escola (CARVALHO, 2012).

Porém, nos dias atuais, muito dificilmente pode obter uma verdadeira democracia sem apreço às diferenças e à justiça social. Desse modo, afirma-se que uma Gestão Democrática só pode se dar de fato, se ela superar burocracias representadas em conselhos e votações e realmente buscar garantir práticas democráticas dentro da escola, nas práticas cotidianas.

Nessa perspectiva, o presente trabalho pretende contribuir com o tema tratado, analisando concomitantemente as relações entre o multiculturalismo e a gestão escolar em nível micro, a fim de colaborar para a compreensão do tema. Argumenta-se que as novas demandas da contemporaneidade, que têm mudado significativamente as sociedades e a educação em geral, também devem tensionar a Gestão Educacional, a fim de que questões relativas à igualdade racial, étnica, de gênero, sexual, religiosa e aspectos relativos à justiça social estejam presentes no cotidiano da escola.

Embora se saiba que o docente tem, em geral, autonomia quando fecha a porta da sala e inicia a sua aula, sabe-se que o gestor de uma instituição educativa pode assumir grande influência na prática dos professores, estimular ou reprimir ações docentes que possam ser caracterizadas como multiculturais.

Do mesmo modo, sabe-se que o gestor tem, sob sua tutela, não somente estudantes, mas também o professorado, que também é uma categoria marcada pelas diferenças, ou seja, também é um público multicultural que, apesar de ter o mesmo objetivo - educar as(os) alun(as)os, ajudando-as(os) a se tornarem cidadãs(os) críticas(os) e emancipadas(os) -, apresentam características culturais diferentes (raça, gênero, sexualidade etc.), bem como diferentes concepções de como se deve ensinar. 


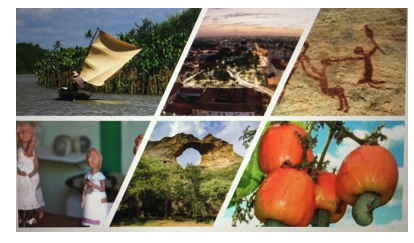

Nessa perspectiva, é do interesse deste trabalho defender a ideia de que uma Gestão Democrática deve, necessariamente, levar em consideração as diferenças culturais presentes no alunado e no professorado. Desse modo, pretende-se buscar pistas que possibilitem o entendimento de como as questões multiculturais perpassam no ideário de gestão escolar de uma escola privada localizada à cidade do Rio de Janeiro.

Para tal, foi adotada uma metodologia triangular de produção de dados. Segundo Ivenicki e Canen (2016), a fim de se produzir dados mais precisos, com rigor e qualidade, pode-se recorrer a três diferentes instrumentos de produção de dados que devem ser aplicados, preferencialmente, em três sujeitos de pesquisa diferentes.

Dessa forma, foi, inicialmente, feita uma análise documental no documento da escola chamado de Boletim Informativo que, segundo a equipe gestora, é a forma reduzida do Projeto Político-Pedagógico da escola. Segundo Caulley (apud LÜDKE; ANDRÉ, 1986), a análise documental, busca identificar informações factuais nos documentos a partir de questões ou hipóteses de interesse.

Após isso, foi feita uma observação presencial do conselho de classe do Ensino Fundamental I. Segundo Ferreira et al. (2012), a observação é um método de produção de dados que se caracteriza pelo fato da(o) pesquisador(a) observar diretamente uma situação ou fenômeno social no interior do mesmo.

Por fim, foi realizada uma entrevista semiestruturada com a diretora adjunta da escola, realizada para se obter dados sobre os sentidos estabelecidos pela fala da gestora sobre a gestão educacional a nível micro, relacionadas às diferenças culturais presentes no alunado e no professorado. Segundo Lüdke e André (1986), entrevista é “o processo de interação social entre duas pessoas na qual uma delas, o entrevistador, tem por objetivo a obtenção de informações por parte do outro, o entrevistado". Sobre o tipo de entrevista que será utilizado no pretendido trabalho - a entrevista semiestruturada - Boni e Quaresma (2005) escrevem que esta não é restritiva como a entrevista estruturada, pois o entrevistador não fica preso às perguntas previamente elaboradas por ele, mas está livre 


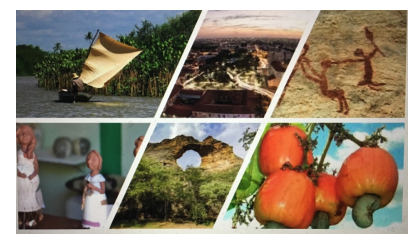

para formular outras perguntas à(ao) entrevistada(o) durante a entrevista, segundo o desenrolar desta e dos objetivos que ele pretende alcançar com a entrevista.

A discussão iniciará no próximo subtópico, que tratará da análise documental do documento criado pela equipe gestora da escola, conhecido como Boletim Informativo.

\section{Análise documental}

Como já foi explicitado, o objeto da análise documental é um documento conhecido como Boletim Informativo, que busca informar pais e alunas(os) sobre as rotinas da escola. É importante ressaltar que inicialmente, pretendeu-se fazer tal análise junto ao Projeto Político-Pedagógico (PPP) da escola, porém, este não foi disponibilizado, sob a alegação de que o Boletim Informativo e o PPP seriam a mesma coisa.

Não se pode afirmar que a escola esteja omitindo alguma informação, ou, simplesmente, esteja com receio, mas tendo em vista o caráter democrático e aberto que todo o PPP, pelo menos teoricamente, deveria ter, questiona-se o porquê de o PPP não ter sido disponibilizado.

Caso o PPP seja realmente igual ao documento analisado, tem-se algumas problemáticas, porque, em geral, o documento apenas explica as regras da instituição e como são feitas as avaliações e calculadas as notas finais. Em outras palavras, é um documento extremamente burocrático e pouco pedagógico.

No que se refere ao trato das questões multiculturais no documento, tem-se que elas, simplesmente, não se fazem presentes no documento. Argumenta-se que a falta desse dado já é um dado: partindo do pressuposto de que uma das funções do PPP é se constituir como um "documento de identidade" de uma instituição, apresentando suas características e objetivos (CANEN; SANTOS, 2009), vê-se que a identidade da instituição aqui analisada vai em direção a uma burocracia exacerbada, pouco humanista e não relacionada com temas contemporâneos. 


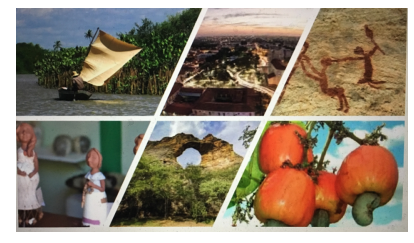

Porém, o PPP representa realmente o pensamento de toda a equipe pedagógica? Tal item será analisado a seguir, quando serão tratados os dados relativos às observações feitas no Conselho de Classe.

\section{Conselho de Classe}

Em maio de 2018, um dos autores deste artigo conseguiu autorização para participar do Conselho de Classe relativo ao primeiro trimestre do ano letivo citado, abrangendo os discentes do ensino fundamental I. Concorda-se com Pimenta e Lima (2006) sobre o fato de tal espaço-tempo ter potencial para ser realizada uma autoavaliação da conduta da equipe pedagógica, porém, o mesmo acaba se limitando, muitas vezes, as lamúrias das(os) docentes, da simples anunciação de notas e de "fofocas acadêmicas", muitas vezes, desnecessárias. No geral, isso coincidiu com o que foi observado.

Cada aluna(o) era tratada(o) individualmente e se analisava as notas da(o) mesma(o). Aquelas(es) que tinham melhores notas, eram rotuladas(os) como boas (bons) alunas(os) e nada mais era tratado. Os comentários eram mais prolongados quando se estava tratando de alunas(os) com notas inferiores ou com problemas de comportamento.

Em alguns momentos, argumenta-se que alguns comentários eram desnecessários e que pareciam tentar "fazer graça" com características de alguns estudantes (modos de se comportar e, em casos mais extremos, características físicas), sendo que tais comentários em nada contribuíam para questões pedagógicas.

Em um caso interessante para as questões multiculturais, foi comentado sobre um menino cujas principais amizades eram meninas e que gostava de usar materiais escolares socialmente estereotipados como "femininos". Um professor chegou a dizer que já conversou com ele para ele "parar com isso". Nada foi comentado sobre o aluno sofrer bullying e o seu comportamento não interfere no seu rendimento escolar, tendo em vista suas boas notas, porém, mesmo assim, o assunto foi levantado, aparentemente, porque parte da equipe de professoras(es) reproduz estereótipos de gênero. 


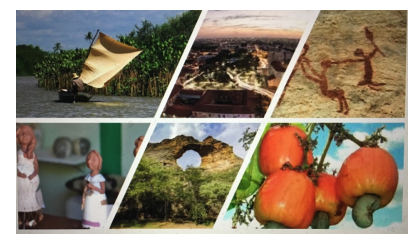

Semelhantemente, foi comentado sobre um pai que imita uma bailarina para receber a filha quando esta está com o uniforme do balé. Nesse momento, uma professora claramente levantou a possibilidade de o pai em questão ser homossexual, o que fez a maior parte dos presentes rir. Outra professora indagou que ele poderia ser somente um "bom pai”, mas, no geral, aparentemente, o comentário de que o homem era gay foi mais bem aceito pelo grupo. Novamente, se reforça que tal comentário em nada ajuda nas discussões que deveriam ser tecidas em benefício dos discentes, como por exemplo as configurações familiares contemporâneas.

Em outro momento, quando se falava de uma discente, uma professora questionou se era ela a criança cuja família é formada por duas mães. Percebe-se o eufemismo em se substituir "casal de mulheres" ou "lésbicas" pela expressão "duas mães", mesmo assim, nota-se um tom de intolerância e preconceito, pois, qual seria a utilidade de se fazer tal comentário naquela ocasião?

Mas, nem tudo são espinhos: em muitas oportunidades, os comentários feitos serviam para tentar deixar os professores e professoras a par de possíveis problemas familiares que poderiam estar impedindo o progresso de certas(os) estudantes, mas, mesmo nesse casos, pouco era discutido sobre como, efetivamente, poder-se-ia ajudar tais estudantes em tais aspectos, o que fazia com que, aparentemente, tais fatos fossem recebidos como fofocas.

Por fim, não pode-se deixar de comentar que, ao se comentar sobre uma discente, uma das diretoras atentou ao fato de que ela já havia cometido atos racistas com colegas e que a equipe deveria estar atenta para rechaçar possíveis atitudes semelhantes que poderiam vir no futuro.

Apesar de tal fala ser extremamente positiva sob uma ótica multicultural, crê-se que a burocracia do momento (dizer notas, escrever atas, assinar fichas) impediu que a equipe pensasse, no momento, em ter atitudes concretas para evitar tais atitudes e não somente rechaçá-las quando viessem a aparecer, mas sim, criar estratégias de prevenção, haja vista 


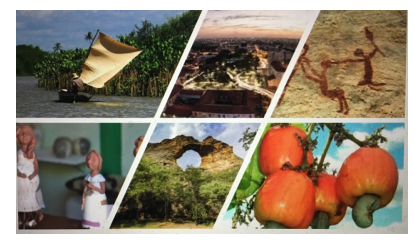

que quando a situação ocorre em relação entre adultos, o racismo é passível de punição judicial.

De forma geral, notou-se um excesso de burocracia, nenhuma autoavaliação da gestão, pouquíssimas recomendações úteis da equipe gestora aos professores e a reprodução de estereótipos preconceituosos por parte da equipe docente e por parte da gestão, principalmente, no que se refere às questões de gênero e sexualidade.

É interessante notar que a equipe pedagógica também é plural, formada por um número quase igual de mulheres e homens (algo incomum no ensino fundamental I), que são, em sua grande maioria, pessoas negras. Porém, é sabido que muitos desses professores e gestores são de alguma filiação cristã, o que pode explicar (mas não justificar) a reprodução de estereótipos relativos ao gênero e a sexualidade, mas não à raça e etnia.

\section{Entrevista}

Por fim, chega-se a parte do texto que trata da entrevista realizada com a gestora. Trata-se de uma das diretoras adjuntas da escola, que já possui alguns anos no cargo e larga experiência como pedagoga. Ressalta-se também que, em um primeiro momento, a intenção era entrevistar a diretora principal da escola, porém esta desmarcou a entrevista, alegando falta de tempo.

O roteiro utilizado na entrevista foi o seguinte:

1 - Quais são os principais desafios que a senhora encontra ao gerir sua escola, de forma geral? Esta pergunta buscou analisar, de antemão, quais as questões vistas como relevantes para a gestora. Com essa pergunta, espera-se obter pistas sobre como as questões multiculturais perpassam as prioridades da gestão daquela escola.

2 - Como é a rotina da gestão da escola e seus principais eventos? Essa pergunta pretendeu verificar se na escola existem reuniões para elaboração de PPP, Conselho de 


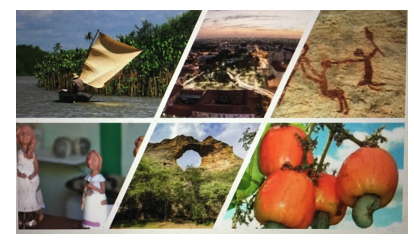

Classes, Conselho Escola-Comunidade e Conselho escolar, considerados nesse texto como condições sine qua non para a existência de uma gestão democrática.

3 - No que se refere à gestão de coordenadoras(es) e professoras(es), quais são os principais itens a serem levados em consideração? Esse questionamento averigua o tratamento da gestão dado às(aos) professoras(es).

4 - No que se refere ao atendimento de pais e alunas(os), como a escola lida dos diferentes casos? Questão com intuito semelhante à anterior, porém, analisando como a gestão atende pais e alunas(os).

5 - Como o PPP da escola foi formulado? Esta questão busca obter dados sobre a participação de professoras(es) e pais na formulação do PPP;

6 - Questões contemporâneas, como diferenças de raça, etnia, gênero, sexualidade, religiosidade, perpassam, de algum modo, na forma com que a escola busca atender às(aos) professoras(es)? Chega-se ao zênite da entrevista, quando se pergunta diretamente se questões multiculturais influenciam ou não na gestão.

7 - E aos pais e alunas(os), tais questões influenciam em abordagens diferenciadas? Tem-se o mesmo aspecto, porém, tratando da gestão de pais e alunas(os).

8 - Como questões relacionadas a preconceitos e discriminações são tratadas pela gestão da escola, no âmbito da gestão de professores e de alunas(os)? Sabendo que a escola é o local onde tudo acontece, obteve-se o tratamento dado pela escola a acontecimentos discriminatórios.

Iniciando a análise da entrevista, ao ser perguntada quais são os principais desafios da gestão, a diretora foi categórica ao dizer que está em "lidar com as pessoas, na questão do comprometimento de todos". A professora também afirma que "hoje em dia, não é como era antigamente, as pessoas fazem apenas de forma trabalhista, existe quem faça por amor, mais a maioria faz somente pela profissão".

Percebe-se nessa fala a já tradicional discussão da educação como profissão ou sacerdócio. De forma bem clara, a professora vê o papel docente como sacerdócio, algo a ser feito com amor. Ela relata que "antigamente quando existia algum problema na 


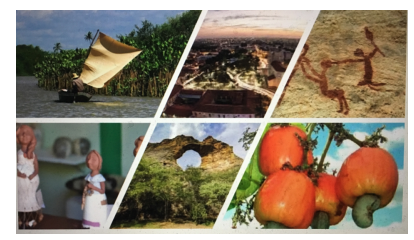

secretaria e o professor percebesse, duvido que ele fosse embora sem prestar ajuda (...), hoje em dia não, deu o horário, vão embora”.

Essa fala pode ser rebatida justamente ao apontar que o trabalho docente não é um sacerdócio, mas sim uma profissão defendida pela Consolidação das Leis do Trabalho (CLT). Embora seja educado prestar ajuda à gestão, caso isto seja necessário, atuar fora do expediente está longe de ser uma obrigação da(o) docente.

Ela também cobra maior participação dos pais e aproximação das(os) estudantes:

Quando eu comecei a trabalhar aqui na escola, nós tínhamos mais pais participativos, nas reuniões, nas festas, os alunos eram mais amigos, eram mais de abraçar, de falar com a gente sobre seus problemas, e hoje é menos, as relações estão mais frias, com todo mundo, pais, alunos e funcionários.

Esse esfriamento das relações, que é algo característico da modernidade líquida, é encarado como algo a ser enfrentado, inclusive, na relação família escola pela docente, o que já foi apontado por Canedo (2013). Porém, apesar da diretora ver tal "esfriamento" ser visto pela diretora como principal desafio da gestão, ela não apontou como a gestão poderia reverter tal quadro.

Em geral, obteve-se dados que estavam mais de acordo com uma filosofia democrática e multicultural, diferentemente de muito daquilo do que se obteve nas observações do conselho. É importante ressaltar que a diretora entrevistada não participou do conselho em questão, o que pode explicar a divergência nos dados. Também vale ressaltar que questões de interesse do multiculturalismo não foram mencionadas na resposta, ou seja, aparentemente, elas não são vistas, pelo menos a priori, como um dos desafios da gestão.

Ao ser perguntada sobre a rotina da gestão e seus principais eventos, percebeu-se que, dos eventos principais da gestão escolar listados por Carvalho (2012) (elaboração do PPP, Conselho de Classe, Conselho Escola-Comunidade e Conselho Escolar), apenas o Conselho de Classe foi citado:

"A escola tem um calendário anual de tudo o que vai acontecer (...), os principais eventos são festa junina, Conselho de Classe, 


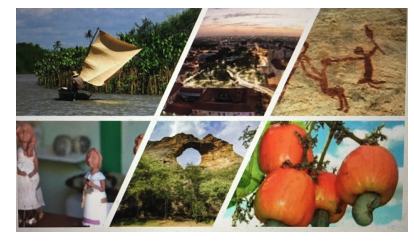

formatura, fechamento de notas, Dia das Crianças... e sempre antes têm reuniões para sabermos como tudo vai acontecer."

Aparentemente, eventos importantes como a elaboração do PPP de forma democrática, Conselho Escola-Comunidade e Conselho Escolar não existem e são ofuscados por festas e celebrações com caráter pedagógico secundário, como Festa Junina e Formaturas. Embora não se negue a importância de tais festas, questiona-se se tais atividades podem tirar o foco da gestão para os outros eventos que não foram citados.

Ao responder como a gestão trata dos assuntos pertinentes às(aos) coordenadoras(es) e professoras(es), a resposta foi em direção à perspectiva da eficácia e do sucesso escolar (BONAMINO, 2012). A gestora afirmou supervisionar as(os) professoras(es) para algumas questões como, "utilização do livro, pois o pai pagou pelo livro e ele quer que o livro seja utilizado", "que a matéria não pode ser jogada, simplesmente por que tem que dar" e "criar estratégias para as crianças que têm dificuldades, pois tem crianças que têm dificuldades mesmo, mas outras podem ter dificuldades por culpa nossa, e aí a gente tem que analisar o que é responsabilidade da escola, dos alunos e dos pais". No geral, vê-se uma preocupação maior da gestão no rendimento dos alunos, o que Bonamino (IBIDEM) vê como uma característica positiva da gestão. Novamente, salienta-se que as questões multiculturais não apareceram nessa etapa do discurso.

A diretora mostrou apreciar bastante da gestão para pais e alunos. Quando perguntada sobre o assunto, ela afirmou que

“educação não é só avaliar o que está no papel, quando você conhece o aluno, você pode falar com propriedade (...), quando você conversa com os pais, você passa para eles informações importante e também recebe informações importantes."

Tem-se, desse modo, a valorização da relação escola-família, algo bem visto pela literatura acadêmica (CANEDO, 2013).

Ao ser indagada sobre o PPP, ela informa que "todo o ano ele é revisado pela equipe pedagógica e é o que se tem no Boletim Informativo". Como tal documento já foi analisado anteriormente, tal assunto não será novamente tratado aqui, mas no decorrer da 


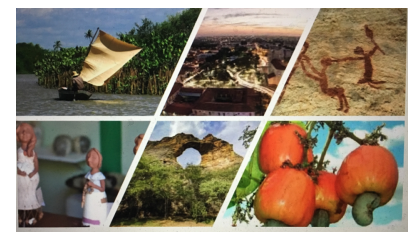

fala, ela diz que o documento também visa levar os discentes a serem "críticos, seres pensantes, com atitudes cidadãos, não só na escola, mas também em todo o lugar", dando como exemplo o caso do assédio que brasileiros fizeram com uma russa que ganhou grandes proporções nas redes sociais e em meios jornalísticos ${ }^{i}$, classificando-o como lamentável. Tem-se, finalmente, algo de interesse do multiculturalismo: trato sobre questões relacionadas às discussões sobre gênero.

Aproveitou-se o assunto para direcionar a entrevista para tratar mais diretamente das questões multiculturais. Ao ser questionada sobre como as questões multiculturais são tratadas na gestão de professoras(es) e coordenadoras(es), a diretora informou dados mais voltados à seleção das(os) profissionais, dizendo que a escola "não tem nenhum problema" e complementa: "Quando eu faço a seleção, a primeira coisa que eu pergunto é sobre a festa junina, e digo que é algo cultural e que a escola não faz nenhuma adoração a Santo" e valoriza as diferenças religiosas da instituição, afirmando o seguinte: "Eu sou católica, a [coordenadora] é adventista, tem gente espírita, então enfim, a gente respeita. A [coordenadora] é adventista e guarda o sábado (...), e quando ela foi trabalhar na escola ela disse isso e isso é respeitado".

Os aspectos citados vão em direção ao respeito e tolerância religiosa dentro do ambiente escolar, mas um observador inquieto não poderia deixar de notar crucifixos em alguns lugares da escola, o que, de certa forma, parece direcionar para as(os) alunas(os) e profissionais, a religião que é vista como correta pela escola, apesar da existência da tolerância ressaltada.

Após tal ponto, a diretora foi arguida sobre como as questões multiculturais influenciam a gestão no que se refere ao tratamento de pais e alunas(os) e ela diz

“Às vezes eu percebo em alguns pais esses preconceitos com os professores, mas nem em questão de sexo, religião, mas de idade, às vezes têm pais que acham que professores bons são só os mais velhos, mas todo mundo tem que começar! 


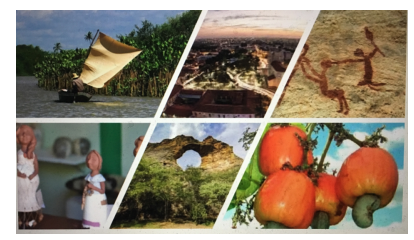

Aqui se tem um ponto interessante, pois a faixa geracional (idade) é um item que começa a ser discutido nos debates multiculturais e a diretora o trás para seu discurso, afirmando que busca rechaçar preconceitos de pais com professoras(es) mais novas(os).

Ela também mostra que tem amadurecido e que a faixa geracional já influenciou nas suas escolhas na escola, porém, não mais influenciam:

Quando tinha época de seleção, a gente dizia, ah, vamos contratar só mulheres, a gente tinha alguns homens, e as meninas ficavam muito de fogo, então homem novinho bonitinho na seleção eu não contratava, pensava que não dava certo, mas depois eu pensei, poxa, que preconceito, porque não? E a experiência foi mostrando que isso não tem nada a ver.

É interessante ressaltar que embora a diretora relate um preconceito superado relativo à faixa geracional, ela também demonstra reproduzir estereótipos de gênero, no caso, com mulheres, pois, em sua concepção, as "meninas" (que não fica claro se são professoras, estagiárias ou alunas) tendem a ficar com "fogo" na presença de homens novos e bonitos, algo que o feminismo iria refutar categoricamente.

Por fim, foi perguntado como a escola lida com alunas(os) que comentem racismos e discriminações. A diretora apresentou como resposta que todas(os) alunas(os) frequentam a Escola da Inteligência, idealizado por Augusto Cury, projeto parceiro da escola, que ensina sobre inteligência emocional e valores. Ela afirma que [a Escola da Inteligência] "trabalha muito isso, a questão das diferenças, de respeitar o próximo, respeitar o ser humano, independente da opção sexual ${ }^{\mathrm{ii}}$ dele, independente da religião, independente da raça".

Esse ponto é muito interessante, pois mostra que a escola tem interesse que seus alunos tenham contato com esse tipo de discussão, por isso, empreendeu esforços, tempo e verba para contratar os serviços de um grupo especializado para tal. Tais esforços não podem ser ignorados e mostram que a escola, de certa forma, se preocupa com as questões de interesse do multiculturalismo, porém, de forma humanista, lidando com elas somente 


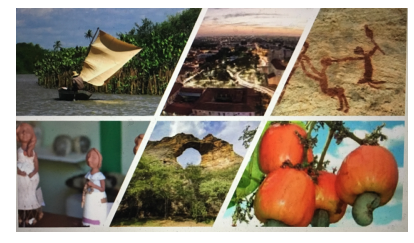

do ponto de vista da tolerância, sem despertar verdadeiramente uma conscientização crítica e o acolhimento.

Ademais, fica como indagação o porquê de a instituição não tomar para si esta responsabilidade, haja vista que a escola é um espaço de tensões e de encontro com a alteridade. Outro ponto que deve ser salientado é se há algum tipo de orientação aos docentes frente a práticas multiculturais.

\section{Considerações Finais}

A triangulação de dados apontou tensões e discrepâncias de como o tema das diferenças é tratado na escola: de forma omissa no Boletim Informativo, como chacota no Conselho de Classe e de forma humanista pela diretora adjunta.

Percebe-se que a "alta cúpula" da gestão (dona da escola e as duas diretoras adjuntas), apesar de hipervalorizar avaliações pontuais, classificatórias e excludentes e, utilizar tal caráter avaliativo como parte da identidade da escola (conforme relatou a análise documental) reconhecem a importância de se tratar de forma positivas as diferenças nas salas de aula, porém, tal atitude não é compartilhada por muitas(os) coordenadoras(es) e professoras(es), que veem o tema como motivos para fazerem piadas.

Sugere-se que a gestão possa buscar envolver melhor as(os) coordenadoras(es) e docentes, para que o trato das diferenças na escola possa se dar de forma mais efetiva e não somente teórica, sob a logomarca do projeto da Escola da Inteligência, pois vale ressaltar, que as(os) mesmas(os) professoras(es) que reproduziram estereótipos no Conselho de Classe são os que ensinam as(os) alunas(os) a não serem preconceituosas(os).

\section{Referências}

ARAUJO, Cinthia Monteiro de. Por outras histórias possíveis: em busca de diálogos interculturais em livros didáticos de história. 2012. Tese (Doutorado em Doutorado) Pontifícia Universidade Católica do Rio de Janeiro, 2012. 


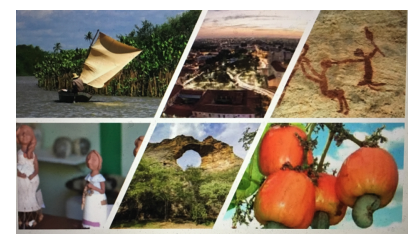

BONAMINO, A. Características da Gestão escolar promotoras de sucesso. In: POLON, T. L. P.; BONAMINO, A. M. C.; PAES DE CARVALHO, C.; ALVES, F. Gestão do Currículo e Gestão e Liderança (Col. Gestão e Avaliação da Educação Pública, vol.3). Juiz de Fora: Editora do CAED, 2012. (p. 117 a 132).

BONI, Valdete; QUARESMA, Silvia Jurema. Aprendendo a entrevistar: como fazer entrevistas em Ciências Sociais. Revista Eletrônica dos Pós-Graduandos em Sociologia Política da UFSC, 2005.

CANEDO, M. L. Um olhar a partir das famílias. In: XAVIER, A.; CANEDO, M. L.; BRANDÃO, Z. (orgs.) Construção da Qualidade de Ensino. Rio de Janeiro: Editora Forma e Ação, 2013.

CANEN, Ana. O multiculturalismo e seus dilemas: implicações na educação. Comunicação e Política, v.25, no 2, p. 91-107, 2007

.; XAVIER, Giseli Pereli de Moura. Gestão do currículo para a diversidade cultural: discursos circulantes em um curso de formação continuada de professores e gestores. Currículo sem Fronteiras, v. 12, n. 2, p. 306-325, maio/ago. 2012

.; SANTOS, A. R. Educação Multicultural: teoria e prática para professores e gestores em educação. Rio de Janeiro: Editora Ciência Moderna, 2009.

CARVALHO, Júlia Gonçalves de . Diversidade cultural e gestão escolar: alguns pontos para reflexão. Rev. Teoria e Prática da Educação, v. 15, n. 2, p. 85-100, maio./ago. 2012

COSTA, Rejane Pinto. O Ensino de Inglês em uma Ótica Multicultural. 2001. Dissertação (Mestrado em Mestrado em Educação) - Faculdade de Educação- UFRJ, 2001.

DANTAS, Marco Aurélio Acioli. GOMES, Alfredo Macedo Gomes. Interfaces entre gestão escolar democrática e a lei $\mathrm{n}^{\circ}$. 10.639/2003. Revista de Administração Educacional, Recife, V. 1 . № 1 . jan./jun 2016 p.90-106

DELATORRE, Catia Silene. A construção da gestão democrática no contexto escolar multicultural. Monografia de especialização em Gestão escolar, UFSM, 2012.

DINIZ-PEREIRA, Júlio Emílio; ZEICHNER, Kenneth (orgs.). Justiça Social: Desafios para a formação de professores. Belo Horizonte: Editora Autêntica, 2008.

DORVILLÉ, Luís; TEIXEIRA, Pedro; SOARES, Camila. Entre dogmatismos e silenciamentos mútuos: o ensino de evolução e as ideias religiosas. In.: Diferenças 


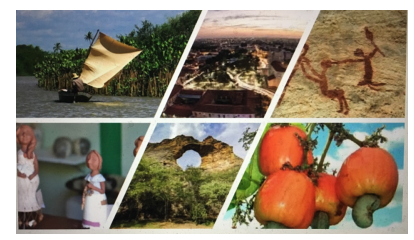

silenciadas: Pesquisas em educação, preconceitos e discriminações. ANDRADE, Marcelo (org.). 1 ed. Rio de Janeiro: 7letras, 2015.

FARIA, Rosa Maria da Silva. O Ensino e a Avaliação de Francês para as Classes Populares: um olhar multicultural. 2009. Dissertação (Mestrado em Educação) Faculdade de Educação- UFRJ, 2009.

FERREIRA, Luciene Braz; TORRECILHA, Nara; MACHADO, Samara Haddad Simões. A técnica de observação em estudos de administração. Congresso da ENANPAD, 2012.

GAY, G. A Synthesis of Scholarship in Multicultural Education. Urban Monograph Series. North Central Regional Educational Lab., Oak Brook, IL. Office of Educational Research and Improvement (ED), Washington, DC, 1994.

GOMES, Joe. Teoria e Prática Multicultural: subsídios para a formação continuada do professor de educação fisica. 2011. Dissertação (Mestrado em Educação) - Universidade Federal do Rio de Janeiro, 2011.

GUIMARÃES, Ana Paula Miranda ; MARTINS, Carine, Belau de Castro; FIGUEIREDO, Priscila Silva de; ALMEIDA, Rosiléia Oliveira de. Multiculturalismo no ensino de biologia na visão de estudantes de uma escola particular do município de dias d' Ávila. Indagatio Didactica, vol. 5(2), outubro, 2013

HALL, Stuart. A identidade cultural na pós-modernidade. 10a ed. Rio de janeiro: dp\&a; 2005.

A centralidade da cultura: notas sobre as revoluções culturais do nosso tempo. Educação Realidade, Porto Alegre, v. 22, n²2, p. 15-46, jul./dez, $2003 \mathrm{a}$. UFMG, 2003b

Da diáspora: identidades e mediações culturais. Belo Horizonte: Editora da

LÜDKE, Menga; ANDRÉ, Marli. Pesquisa em Educação: abordagens qualitativas. São Paulo: Editora Pedagógica e Universitária, 1986.

MIGON, Cristiane Abreu; NOGUEIRA, Monique Adries. Possibilities and limits of a multi/intercultural music appreciation at schools. Literacy Information and Computer Education Journal (LICEJ), v. 6, p. 1371-1378, 2015.

OLIVEIRA, Luiz Fernandes de. Histórias da África e dos africanos na escola: perspectivas para a formação dos professores de história quando a diferença se torna obrigatoriedade. 2010. Tese (Doutorado em Doutorado) - Pontifícia Universidade Católica do Rio de Janeiro, 2010. 


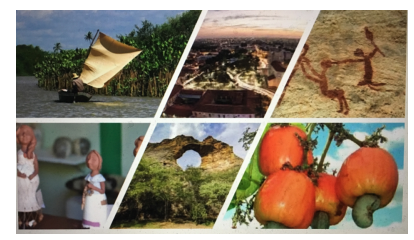

PAES DE CARVALHO, C.; LIMA, M. F. M. Conselhos Escolares, gestão democrática e Qualidade do ensino em escolas da rede pública municipal do Rio de Janeiro: percepções e pais e professores. Boletim SOCED, n. 8, 2012.

PIMENTA, Selma Garrido; LIMA, Maria Socorro Lucena. Estágio e docência: diferentes concepções. Revista Poíesis -Volume 3, Números 3 e 4, pp.5-24, 2005/2006

SALLES, Fabiano Lages. Educação Física, Currículo e Identidades em um Contexto Escolar: um olhar multicultural. 2014. Dissertação (Mestrado em Educação) Universidade Federal do Rio de Janeiro, 2014

SANTOS, Ana Paula da Silva. A Educação Física em uma Perspectiva Mul/Intercultural e as Relações de Gênero no Contexto Escolar. 2013. Dissertação (Mestrado em Mestrado em Educação) - Faculdade de Educação- UFRJ, 2013.

SILVA, Rita Cassia de Oliveira e. Formação Multicultural de Professores de Educação Física: entre o possível e o real. 2008. Dissertação (Mestrado em Mestrado em Educação) - Faculdade de Educação- UFRJ, 2008.

SOUZA, Deyse Medeiros de. LIMA, Erika Roberta Silva de Lima, SILVA, Ciclene Alves da. A presença do multiculturalismo e da democracia nos processos organizacionais da escola pública. Revista Ensino Interdisciplinar, v. 1, n⿳0.03, Dezembro/2015 UERN, Mossoró, RN

VIEIRA, S. L. Escola - lugar onde tudo acontece. In: VIEIRA, S. L. Educação Básica: política e gestão da escola. Brasília: Liber Livro, 2009. (p. 149 a 160).

VIEIRA, S. L. Política(s) e Gestão da Educação Básica: revisitando conceitos simples. Revista Brasileira de Administração da Educação - RBPAE. v.23, n.1, p. 53-69, jan./abr. 2007. 


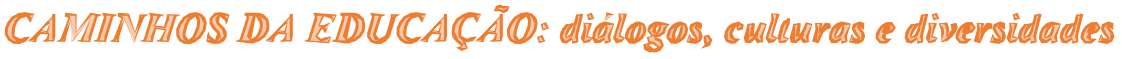

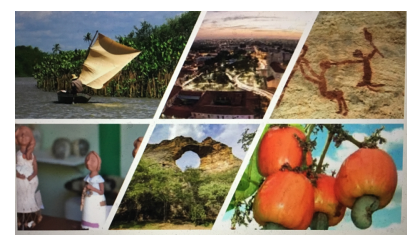

